\title{
Synergistic Effect of Metformin and Vemurufenib (PLX4032) as a Molecular Targeted Therapy in Anaplastic Thyroid Cancer - An In Vitro Study
}

\section{Latha Durai}

Cancer Institute

\section{Soundharya Ravindran}

Cancer Institute

Devarajan Karunagaran

Indian Institute of Technology Madras

Krishnamurthy Arvind

Cancer Institute

Ramshankar Vijayalakshmi ( $\nabla$ r.vijayalakshmi@cancerinstitutewia.org )

Cancer Institute https://orcid.org/0000-0001-6890-4231

\section{Research Article}

Keywords: Anaplastic thyroid cancer, Metformin, Vemurafenib, Thyroid stimulating hormone receptor, cyclic AMP signaling

Posted Date: May 18th, 2021

DOl: https://doi.org/10.21203/rs.3.rs-516220/v1

License: (c) (1) This work is licensed under a Creative Commons Attribution 4.0 International License. Read Full License 


\section{Abstract}

Survival rate of patients with anaplastic thyroid carcinoma (ATC) is less than $5 \%$ with current treatment. Deregulated cell signaling pathways such as BRAF/MAPK/ERK pathway and AMPK pathway along with suppression of iodine metabolising genes including NIS and TSHR are seen in ATC. In ATC, BRAF ${ }^{\mathrm{V} 600 E}$ mutation is the major mutation occurring in ATC that constitutively activate MAPK/ERK signaling and result in the transformation of normal cells in to undifferentiated cancer cells. Although Vemurufenib is a selective oral drug for the BRAF ${ }^{\mathrm{V} 600 \mathrm{E}}$ mutant kinase with a response rate of nearly $50 \%$ in metastatic melanoma, our study on ATC has showed resistance to Vemurafenib. Metformin, a diabetic drug is an AMPK activator and has recently proved to be involved in preventing or treating several types of cancer. Using iGEMDock software, a protein-ligand interaction was successful between Metformin and TSHR in our study and demonstrated that combination of Vemurufenib with metformin has synergistic anti-cancer effects and provide the evidence that the combination of drugs suppressed the progression of ATC cells growth by inducing significant apoptosis through downregulation of ERK signaling, upregulation of AMPK pathway and by reversing epithelial-mesenchymal transition (EMT) markers - E-cadherin and Vimentin expression. Our results suggest that Metformin act as a demethylating agent in anaplastic thyroid cancer cells by inducing the expression of NIS and TSHR. CAMP signaling has been studied in ATC for the first time through our study wherein CAMP signaling is downregulated due to decrease in intracellular cAMP level upon metformin treatment. To conclude, our findings demonstrate novel therapeutic targets and treatment strategies for undifferentiated ATC.

\section{Introduction}

Thyroid cancer is one of the most common endocrine malignancies and its incidence is rapidly increasing worldwide. Thyroid cancer is classified into well-differentiated tumors such as papillary and follicular carcinomas and undifferentiated tumors such as anaplastic carcinoma. Although majority of differentiated thyroid tumors respond well to therapy, anaplastic thyroid cancer is untreatable due to high malignant potential where patients succumb within six months of diagnosis despite intensive treatment approaches including surgery, chemotherapy and radiation [1], [2]. Several previous studies have demonstrated molecular therapies targeting epidermal growth factor receptor [EGFR] [3], peroxisome proliferator activated receptor $\mathrm{Y}$ (PPAR- $\mathrm{y}$ ) [4], mTOR inhibitor [5]. Despite different therapeutic approaches, treatment for ATC has not changed over past decades due to poor response rate. Hence identifying a novel therapeutic approach and understanding the underlying molecular mechanisms of undifferentiated thyroid cancer is highly desirable to improve patient survival. Studies have showed that approximately $40 \%$ of the ATC tumors contain BRAF mutations [6]. The proto-oncogene BRAF is situated on 7q24 encodes a serine/threonine kinase, transduces regulatory signals via growth factors, hormones and cytokines and are involved in the regulation of cell proliferation, differentiation and apoptosis through the RAS/RAF/MEK/ERK cascade. Mutation in the BRAF gene results in aberrant activation of ERK signaling and induce tumorigenesis in several human cancers including, melanoma, thyroid and colon carcinoma [7-9]. 
Undifferentiated ATC is associated with loss of expression of genes involved in iodine transport and organification such as sodium/iodide symporter (NIS) gene, TSHR (Thyroid stimulating hormone receptor), TPO (Thyroperoxidase), TG (Thyroglobulin), FOXE1 and TTF1 [10]. Loss of NIS and TSHR expression are due to methylation in their promoter region and hence tumors in ATC can no longer respond to radioactive iodine therapy or thyroid stimulating hormone (TSH) suppressive therapy [11]. EMT is a central program stimulated during embryogenesis and development that converts a polarizedepithelial cell into a mesenchymal cell with higher motility capacity which is determined by loss of Ecadherin and increased vimentin expression. EMT is associated with the invasion of cancer to distant organs, metastatic dissemination, and poor clinical prognosis in various human tumors including thyroid carcinomas [12], [13] In ATC, deregulation of BRAF/MEK/ERK and AMPK pathways lead to upregulation of numerous oncoproteins and EMT progression with loss of E-cadherin and increased vimentin expression [14], [15].

Vemurafenib (PLX4032), an inhibitor of BRAF V600E mutated kinase inhibits mutated serine-threonine kinase BRAF by selectively binding to the ATP-binding site of BRAF V600E kinase and improve survival among patients with BRAF ${ }^{V 600 E}$ mutant cancers [16-18]. Eventhough vemurafenib plays pivotal role in BRAF mutant driven tumorigenesis, not all tumor types respond uniformly to BRAF-targeted therapy for eg ATC. Hence the research demands to explore combinational therapy as it is successful in some of the cancer types [19]. In epidemiological studies, it has been reported that diabetic patients taking metformin drug for the treatment are reported to have smaller thyroid volumes, reduced incidences of nodular goiter, and higher remission rates from thyroid cancer [20]. At the molecular level, metformin a potentiator of AMPK activity several studies have demonstrated the ability of AMPK to block tumorigenesis after treating the cancers with pharmacological AMPK activators such as metformin. Nonetheless the exact mechanism by which metformin activates AMPK, and if AMPK is the primary therapeutic target of metformin, are still under argument [21]. Similarly the effect of cAMP signaling have not yet studied in ATC tumorigenesis even though thyrocytes growth, function and production of NIS are occurring mainly through TSHR mediated cAMP signaling [22]. Thus studying the signaling pathway-related targets may provide exceptional opportunities for the development of novel treatment strategies for ATC.

In the present study, we investigated the combination of metformin with vemurafenib in anaplastic thyroid cancer cells; to characterize its influence on different signaling cascade such as B-RAF/ERK; AMPK pathway and cAMP signaling and thereby to determine its effect on cell proliferation, iodide metabolising genes and apoptosis in anaplastic thyroid cells.

\section{Materials And Methods}

\section{Reagents}

Metformin, 5'-Azacytidine (Aza), Forskolin, 3-isobutyl-1-methylxanthine (IBMX) and $\beta$-Actin (ACTB) antibody were purchased from Sigma Aldrich. Vemurafenib (PLX4032) was purchased from Sigma Aldrich. Antibodies for ERK, p-ERK, AMPK, p-AMPK, NIS, E-cadherin and Vimentin were purchased from 
Cell signaling Technology, USA. Versene, D-luciferin and coelentrazine were purchased from Invitrogen. Annexin V-FITC kit Early Apoptosis Detection Kit was purchased from Cell Signalling Technology. LANCE cAMP kit was purchased from PerkinElmer, USA. pGL4.29: A constitutive human CRE expression vector was a kind gift from Prof Karunagaran Devarajan.

\section{Molecular Docking: Protein structure retrieval and preparation}

The three dimensional structure of the Thyroid Stimulating Hormone Receptor (TSHR) was retrieved from the RCSB Protein Data Bank (https://www.rcsb.org/). The proteins' unique PDB ID: $3 G 04$ was saved in the protein data bank format with a resolution of $2.55 \AA$. The structure was modified using the BIOVIA Discovery Studio. The water molecules and the bound ligands were visualised and removed from the structure prior to docking and was stabilised with the addition of Hydrogen and Polar molecules. The modified structure was saved in the PDB format.

\section{Ligand structure retrieval and preparation}

The chemical compounds to be docked against the TSHR were retrieved from the PubChem database (https://pubchem.ncbi.nlm.nih.gov/). The three-dimensional structure of the drug Metformin, with the molecular formula $\mathrm{C} 4 \mathrm{H} 11 \mathrm{~N} 5$ and molecular weight $129.16 \mathrm{~g} / \mathrm{mol}$ was downloaded with its unique PubChem ID: 4091 in the SDF format. The ligand was then viewed and modified using the BIOVIA Discovery Studio and the converted form was saved in the Sybl/MOL2 format. The 2-D and 3-D conformer of the drug is shown as follows

Similarly, the three-dimensional structure of the drug Vemurafenib and de-methylating agent 5Azacytidine were retrieved from the PubChem database. Vemurafenib with the molecular formula $\mathrm{C} 23 \mathrm{H} 18 \mathrm{CIF} 2 \mathrm{~N} 303 \mathrm{~S}$ and molecular weight $489.9 \mathrm{~g} / \mathrm{mol}$ was downloaded in the SDF format using the compound unique ID 42611257. The ligand structure was viewed using the BIOVIA software and was saved in the Sybl/MOL2 format compatible to the docking software. The structure of the de-methylating agent 5-Azacytidine was retrieved from the PubChem database. The molecular formula of the drug is $\mathrm{C} 8 \mathrm{H} 12 \mathrm{~N} 405$ and the molecular weight is $244.2 \mathrm{~g} / \mathrm{mol}$, the structure was downloaded in SDF format using the unique ID: 9444. The ligand structure was viewed and verified using the BIOVIA visualiser and was saved in the sybl/MOL2 format compatible to the docking software used.

The receptor TSHR and the ligands Metformin, Vemurafenib and 5-Azacytidine were docked using the iGEMDOCK V2.1 software suite which is a complete standalone docking and virtual screening tool. The software is advantageous as it gives both the interactive surface to prepare the binding site of the protein and also serves as a visualisation software to view the docked poses. The software docks each of the ligand molecule with the receptor using the in-house tool GEMDOCK. iGEMDOCK generates proteincompound interaction profiles of Electrostatic $(E)$, Hydrogen-Bonding $(\mathrm{H})$ and Van der Waals interaction (V). iGEMDOCK groups the compounds for analysis based on the pharmacological interactions between the compounds and the protein structure. Finally, the iGEM software ranks the binding energy of the compounds by combining the interactions and energy based scoring of GEMDOCK. In the iGEMDOCK 
software the opening page allows the upload of the receptor and the ligand molecules and the parameters were set to the default range. On completion the interaction profile is generated which can be visualised using the in-built rasmol. And the interaction binding and the energy are analysed using the BIOVIA Visualiser studio, which allows to view the bond length and the amino acid interaction profile.

\section{Cell Culture}

T-238, BCPAP (BRAF mutant) and HTH7 (wild type) cell lines were obtained as a kind gift by Dr Manoj Garg, NUS, Singapore, which were maintained in RPMI 1640 media (Roswell Park Memorial Institute 1640 Medium) supplemented with $10 \% \mathrm{FBS}$ (Fetal bovine serum) at $37^{\circ} \mathrm{C}$ in $5 \% \mathrm{CO}_{2}$ and Penicillin (100 units/ml)/streptomycin (100 $\mu \mathrm{g} / \mathrm{ml})$ (Gibco, Grand Island, NY, USA).

\section{Cell Proliferation assay}

The antiproliferative effect of metformin, vemurafenib and the combination of both were evaluated using MTT assay. This is a colorimetric quantitative assay which is measured by quantifying the formation of formazan crystals due to reduction of MTT tetrazolium by live cells. Briefly, $5 \times 10^{3}$ cells were seeded into each well of a 96 well plate and allowed to attach overnight. Then, cells were treated with metformin or vemurafenib or the combination of both and incubated for 24 and $48 \mathrm{~h}$. The untreated cells were used as negative control. After $48 \mathrm{~h}$ of treatment, MTT solution $(0.5 \mathrm{mg} / \mathrm{ml})$ was added to each well and incubated for about $3 \mathrm{~h}$. Dark blue formazan crystals formed, implying the presence of viable cells on solubilization with DMSO. Non-viable cells do not form those crystals. The absorbance was measured by a microplate reader at $570 \mathrm{~nm}$.

\section{Colony formation assay}

Colony formation assay is used to demonstrate the colony forming capacity of a single cell during treatment.T238 cells were grown in 6-well culture plates (1000 cells/well) and after $24 \mathrm{~h}$, they were treated with different concentration of metformin, vemurafenib and the combination of both. Treated cells were incubated at $37^{\circ} \mathrm{C}$ and $5 \% \mathrm{CO}_{2}$ for $10-14$ days till the formation of optimal clones. After incubation, cells were fixed with methanol and stained with Crystal violet.

\section{Annexin V-FITC assay}

Annexin V-FITC assay is used to detect early apoptosis where the cells were stained by both $\mathrm{PI}$ and Annexin V-FITC. Expression of phosphatidylserine, which occurs through the binding of Annexin V-FITC to the cancer line cell surface, indicates apoptotic cells. Further staining with propidium iodide, a nonpermeable DNA dye, indicates necrotic cells. After 48 hours of treatment with metformin, vemurafenib or the combination of both, T238 cells were detached by trypsin, washed with PBS and then resuspended with Annexin V binding buffer. To each aliquot of $96 \mu \mathrm{l}$ cell suspension, $1 \mu \mathrm{l}$ of Annexin V-FITC conjugate and $12.5 \mu$ of propidium lodide (PI) solution were added and incubated for $10 \mathrm{~min}$ on ice in the dark. This 
was diluted to a final volume containing $250 \mu$ /assay with ice-cold 1X Annexin V binding buffer and analyzed using a BD FACSVERSE flow cytometer with an in-built BD FACSuite ${ }^{\mathrm{TM}}$ Software.

\section{RT-PCR}

T238 cells were treated with Metformin, Vemrafenib or the combination of both. After $48 \mathrm{~h}$ of treatment, total RNA from treated T238 cells was extracted by TriZol reagent as per the manufacturer's protocol (Invitrogen, USA). To estimate the mRNA levels, reverse transcription was done using oligodT based conversion of mRNA to CDNA and were amplified using appropriate gene-specific PCR primers. Detection and quantitation of EMT markers and internal control $\beta$-Actin were performed using DyNAmo ColorFlash SYBR Green qPCR Kit reagent (\#F416L, Thermo Scientific, USA). Relative expression levels of genes analyzed were calculated using $2-\Delta \Delta C T$ method by normalizing with internal control $\beta$-Actin.

\section{Western Blot}

T238 cells were treated with Metformin, Vemrafenib or the combination of both. After $48 \mathrm{~h}$ of treatment, total cell lysates were prepared by incubating the treated and untreated cells on ice with RIPA lysis buffer $(150 \mathrm{mMNaCl}, 1 \% \mathrm{NP} 40,0.5 \%$ deoxycholate and $1 \% \mathrm{SDS})$ for $1 \mathrm{~h}$. Protein concentration was then quantified by following Bradford's method. 30ug of protein lysates were resolved on 10\% SDS-PAGE gel and later transferred to PVDF membrane (Immunoblot, Bio-Rad) at constant current of $220 \mathrm{~mA}$ for 1-1/2 hours. The membrane was probed by primary antibody, washed thrice with TBS-T and TBS separately and again probed with secondary antibody conjugated with HRP. Bands were visualized by using the Enhanced Chemiluminescence kit (Bio-Rad), detected by using ChemiDoc and analysed by densitometry (Image Lab, Bio-Rad).

\section{Measurement of cAMP signaling and intracellular cAMP concentration in Anaplastic Thyroid cancer cells}

CAMP signaling apart from thyrocyte growth in thyroid gland, play an important role in the expression of differentiation markers such as NIS, TG and TPO that are responsible for iodide uptake [11]. cAMP is an important second messenger in mediating the cell signaling and hence it is vital to study the cAMP signaling and to measure the intracellular cAMP concentration. Lucifrease Reporter assay and PerkinElmer Lance cAMP kit

\section{Luciferase Reporter Assay}

T238 Cells were transfected with pGL 4.29 luciferase construct which possess CRE (CAMP response element) and luciferase gene. The medium was changed next day, and cells were treated with Forskolin or Metformin or both. After $48 \mathrm{~h}$, cells were lysed using passive lysis buffer and dual luciferase assay was performed using luciferase assay buffer containing $25 \mathrm{mM}$ glycylglycine, $15 \mathrm{mM}$ phosphate buffer at $\mathrm{pH}$ 8.0, $4 \mathrm{mM}$ EGTA, $2 \mathrm{mM}$ ATP, $1 \mathrm{mM}$ dithiothreitol, $15 \mathrm{mM}$ magnesium sulfate and $75 \mu \mathrm{M}$ luciferin and internal control assay buffer containing $1.1 \mathrm{M} \mathrm{NaCl}, 2.2 \mathrm{mM}$ disodium EDTA, $0.72 \mathrm{M} \mathrm{KH} 2 \mathrm{PO} 4,0.44$ $\mathrm{mg} / \mathrm{mL}$ bovine serum albumin (BSA), $1.3 \mathrm{mM}$ sodium azide and $1.43 \mu \mathrm{M}$ coelenterazine. The luciferase 
activity was measured in a luminescence plate reader (Molecular Devices Inc., USA), with renilla luciferase as the internal control.

\section{Measurement of Intracellular cAMP assay}

Intracellular cAMP concentration was measured by using the Lance cAMP kit (PerkinElmer Corp., Waltham, MA). T238 cells were seeded in 24 well plates and next day the assay was performed by dissociating them with versene and by suspending in assay buffer (HBSS, 5 mM HEPES, 0.5 mM IBMX, and $0.1 \% \mathrm{BSA}$ ) at $2.0 \times 10^{6} \mathrm{cells} / \mathrm{ml}$. Cells were added in white OptiPlate-384 microplate from PerkinElmer and the protocol was continued as per manufacturer's instructions. Samples treated with Forskolin, Metformin or both were measured in triplicates using a PerkinElmer multiplate reader.

\section{Statistical analysis}

Each experiment was repeated at least three times. Concentration-dependent curves and statistical analyses were done with GraphPad Prism 4.0 (GraphPad Software, Inc., San Diego, CA). Analyses included mean \pm sem, one- or two-way ANOVA, and Bonferroni post-test wherever appropriate $(*, P<0.05$; $\star \star, P<0.01$; and $* \star *, P<0.001)$. The differences between test and control groups were analyzed using the Graph Prism Program. T-test was used to calculate the P-value of two groups compared. Values of $P \leqslant 0.05$ were considered to be statistically significant. Relative density of western blot bans were quantified using ImageJ software.

\section{Results}

\section{Molecular docking of drugs with Thyroid stimulating hormone receptor (TSHR)}

TSHR is methylated in the promoter region and hence TSHR-cAMP signaling mediated thyroid-specific genes including sodium iodide symporter (NIS) is frequently lost in thyroid cancer. Therefore in order to analyze the drug targets at the TSHR protein; drugs such as Metformin, Vemurafenib and 5-Azacytididne were docked with TSHR using iGEMDOCK software and docked scores of those molecules were represented in Table 1, with their binding energy, Vanderwaal energy, electrostatic and hydrogen bond profiles. It is important to explain the binding energies of the protein-ligand (drug) interactions to elaborate exactly how fit the drug binds to the target macromolecule. It has been observed that drugs (Ligands) such as Metformin (binding energy score $=-65.1694$ ), Vemurafenib (binding energy score $=$ -113.236) and 5-Azacytididne (binding energy score $=-114.015$ ) significantly docked into the binding pockets of TSHR protein. The results show that all the three compounds Metformin, Vemurafenib and 5Azacytidine bind efficiently to the TSHR and the interaction profile of the drugs along with bond length is shown in Figs. 1a, b, c. Further in order to analyze the relationship between metformin and vemurafenib with the TSHR protein, the docked poses were combined and it was observed that both the drugs bind to similar binding site of the protein with a structural overlap as shown in Figure 1d

\section{Sensitivity of Vemurafenib to different thyroid cancer cells}


To examine the sensitivity of vemurafenib to different thyroid cancer cell lines HTH-7 (BRAF ${ }^{\mathrm{WT}}$ ATC cell line), BCPAP (BRAF ${ }^{\mathrm{V} 600 \mathrm{E}}$ mutant, PTC cell line) and T238 (BRAF ${ }^{\mathrm{V} 600 \mathrm{E}}$ mutant, ATC), were treated with different concentrations of vemurafenib and measured the cytotoxicity by MTT assay after $48 \mathrm{~h}$ of treatment. Vemurafenib as a single agent inhibited the cell growth in BRAF mutant BCPAP papillary thyroid cells whereas BRAF mutant T238 anaplastic thyroid cells showed resistance to vemurafenib and BRAF wild type HTH7 cells were also not significant sensitivity to vemurafenib as shown in Figs. 2 a,b

\section{Sensitivity of Metformin to different thyroid cancer cells}

To identify the effect of Metformin on different thyroid cancer cells, HTH-7, BCPAP and T238 cells were treated with different concentrations of Metformin and measured the cytotoxicity after $48 \mathrm{~h}$ of treatment. Metformin did not show any effect on $\mathrm{HTH} 7$ cells (BRAFWT ATC cell line) and BCPAP cells (BRAF $B R A F^{V 600 E}$ mutant, PTC cell line) as shown in Figure $2 \mathrm{c}$ whereas in T238 cells, single agent metformin inhibited cell growth at an $\mathrm{IC}_{50}$ value (50\% reduction in cell viability) of $5 \mathrm{mM}$ and demonstrated a concentration-dependent cytotoxicity profile as shown in Figure 2d. T238 anaplastic cells were used in subsequent experiments as vemurafenib-resistant anaplastic thyroid cancer cell line to study its sensitivity towards the combinational therapy of vemurafenib and metformin.

\section{Combination of metformin and Vemurafenib increases the cytotoxicity of ATC cells}

Efficacy of Metformin and Vemurafenib on ATC as a combinational therapy and to compare the same with the individual therapy is demonstrated by treating T238 cells (BRAF mutant anaplastic thyroid cancer cell line) with different concentration of metformin/vemurafenib individually and with the combination of both. After $48 \mathrm{~h}$ of treatment, cytotoxicity/antiproliferative effect was evaluated using MTT assay wherein the combinational therapy showed increase in cytotoxicity when compared to individual therapy therapy. Control (without any treatment) did not contribute to cytotoxicity (Figure 2e).

\section{Metformin, Vemurafenib and their combination inhibits the colony formation in anaplastic thyroid cancer cells}

In order to determine whether metformin or vemurafenib or their combination possess anticancer effect, a colony formation assay or clonogenic assay was done. Colony formation assay is an in-vitro cell survival assay designed to measure the ability of a single cell to grow into a colony. This assay assesses the anchorage independent growth of cancer cells which is one of the hallmarks of cancer. T238 cells were treated with $5 \mathrm{mM}\left(\mathrm{IC}_{50}\right)$ of Metformin, $50 \mu \mathrm{M}$ Vemurafenib and the combination of both drugs and incubated for 14 days. The results confirm that combination of $5 \mathrm{mM}$ Metformin and $50 \mu \mathrm{M}$ Vemurafenib treatment were resulted in drastic decrease in the ability of T238 single cells to grow into colonies when compared to individual drug treatment. Untreated T238 cells were used as a control (Figs. $3 \mathrm{a}, \mathrm{b})$

Combination of Metformin and Vemurafenib induces apoptosis in anaplastic thyroid cancer cells 
Apoptotic cell death of anaplastic cells were analysed in flow cytometry using Annexin V-FITC assay. As expected, a single agent vemurafenib induced $20.84 \%$ of apoptosis in the BRAFV600E mutant cell line T238, however no effect was seen with single agent metformin treatment. Interestingly, combination treatment ( $50 \mu \mathrm{M}$ vemurafenib and $5 \mathrm{mM}$ metformin) of these cells resulted in $65 \%$ apoptosis. These results imply that combinational treatment significantly induced cell death (three times) when compared with single agent vemurafenib treatment. Figs. $4 a$, $b$.

\section{Study of iodide metabolizing genes involved in thyroid metabolism with and without treatment of vemurafenib, metformin and 5-Azacytidine}

lodide metabolizing genes such as NIS (Na/I symporter), TSHR (Thyroid stimulating hormone receptor), TPO (Thyroperoxidase), TG (Thyroglobulin), FOXE1 and TTF1 were analyzed by quantitative Real time PCR in T238 cells relative to normal thyroid cell line N-Thy. The results demonstrate that the mRNA levels of the genes were very low as shown in Figure $5 \mathrm{a}$. In order to induce the expression of the silenced genes, T238 cells were treated with metformin at the $\mathrm{IC}_{50}$ value of $5 \mathrm{mM}$ and after $48 \mathrm{~h}$ of treatment, mRNA expression was measured and the result demonstrates that metformin treatment increased the mRNA levels of NIS, TSHR, TG, TTF1. It has been reported that low level of gene expression is due to methylation of genes and hence metformin treatment was compared with that of demethylating agent 5-Azacytidine $(10 \mu \mathrm{M})$, wherein interestingly metformin treated cells expressed higher mRNA levels than 5-Azacytidine and reveals that metformin may act as a demethylating agent (Fig $5 b$ ). To further activate the gene expression levels, cells were treated with combination of $5 \mathrm{mM}$ metformin and $50 \mu \mathrm{M}$ vemurafenib, however neither vemurafenib as a single agent nor the combination with metformin increased the expression levels (Fig 5b). Simultaneosly, protein level of NIS was also measured by western blot and the result confirmed that metformin treatment on T238 cells enhanced the protein level of NIS as shown in Figure 7.

\section{Combinational therapy reverses the altered EMT markers expression better than demethylating agent 5- Azacytidine}

To reverse the EMT pathway in BRAF mutant anaplastic thyroid cancer, T238 cells were treated with 5 $\mathrm{mM}$ metformin, $50 \mu \mathrm{M}$ vemurafenib or combination of both and with $10 \mu \mathrm{M}$ of 5-Azacytidine. After 48 hours of treatment, RT-qPCR was performed to evauate the mRNA of E-cadherin and Vimentin. Combinational treatment reversed the pathway significantly by upregulating E-cadherin and by downregulating vimentin whereas reasonable reverse of EMT markers is seen in single agent metformin treatment. However, no effect was seen with of 5-Azacytidine and vemurafenib treatment (Figs. 6 a,b). Simultaneously, western blot was performed to analyse the protein expression wherein the protein level expression is increased in E-cadherin and decreased in Vimentin as shown in Figure 7. The results thus confirm combinational treatment reversed the altered EMT pathway in anaplastic cells.

\section{Study of cell signaling alterations in anaplastic T238 cells}


We next explored different signaling pathways up-regulated or down-regulated by drug treatment and evaluated changes in phospho-protein levels of ERK and AMPK pathways to identify the effects of the single agent or combinational treatment of $5 \mathrm{mM}$ Metformin and $50 \mu \mathrm{M}$ vemurafenib in T238 cell line. Single agent metformin had moderate effects on pERK whereas combinational treatment synergistically downregulated pERK protein levels significantly. Metformin alone upregulated the pAMPK protein level whereas single agent vemurafenib and combinational treatment did not show alterations on PAMPK protein levels as shown in Figure 7. Thus the results demonstrate that metformin targets the AMPK pathway by increasing the p-AMPK protein level whereas combinational treatment targets ERK signaling by decreasing the $\mathrm{p}$-ERK protein level in BRAF mutant ATC.

\section{Metformin downregulates cAMP/PKA signaling by lowering the intracellular cAMP level}

T238 cells were transfected with CRE reporter plasmid pGL 4.29, treated with an increasing concentration of forskolin and the luciferase activity was measured after $48 \mathrm{~h}$ (Figure 8a). Our study shows that the cAMP signaling is increased with increasing concentration of forskolin in T238 cells. Our results found that metformin increased the p-AMPK level and hence we hypothesize to identify the effect of metformin on cAMP signaling. T238 cells were transfected with plasmid pGL 4.29, treated with $30 \mu \mathrm{M}$ Forskolin, 5 $\mathrm{mM}$ metformin or both and the luciferase activity was measured after 48 hours. Interestingly, our results showed decrease in luciferase activity when the cells were treated with $30 \mu \mathrm{M}$ Forskolin and $5 \mathrm{mM}$ metformin which demonstrates that metformin inhibits the CAMP mediated signaling as shown in Figure $8 \mathrm{~b}$. In order to determine whether the metformin lowers the cAMP signaling by decreasing the cAMP production or by inhibiting the PKA mediated cascade, intracellular cAMP concentration is measured. cAMP standard curve assay was performed in 96 well microplates (each well with 3000 cells) in a total volume of $24 \mu$ by using different concentrations of cAMP and the lance signal (TR-FRET) was measured at $615 \mathrm{~nm}$ on PerkinElmer EnVision as shown in Figure 9a. Simultaneously, forskolin dose-responsive curve was performed on T238 cells with $30 \mu \mathrm{M}$ forskolin as shown in Figure 9b. The resulting signals were directly proportional to the cAMP concentration of the cells. $0.5 \mathrm{mM}$ IBMX (Phosphodiesterase inhibitor) was used in all the assays in order to prevent the reduction of LANCE signal produced by CAMP. Following the standard assays, an assay is performed by treating the cells with $5 \mathrm{mM}$ metformin and 30

$\mu \mathrm{M}$ forskolin. The fluorescence intensities were then measured at $615 \mathrm{~nm}$ and found the lance signals were decreased as shown in Figure 9c. Lance signal counts at $615 \mathrm{~nm}$ obtained in cAMP standard curves will allow the determination of the amount of cAMP produced in stimulated cells [23]. Based on this assay, it has been found that intracellular CAMP levels were reduced in metformin treated cells (Table 2) and thus our results confirm that metformin downregulates cAMP signaling by decreasing the intracellular cAMP level.

\section{Discussion}

Current treatment for undifferentiated and aggressive anaplastic thyroid cancer remains ineffective and are associated with incurability and patient mortality [24]. Majority of ATC has BRAF mutation; resulting in the unusual activation of ERK signaling, downregulation of AMPK signaling and induce EMT which in 
turn result in invasion and metastasis of cancer [25], [26]. Therapeutics blocking this signaling pathway; for instance BRAFV600E inhibitor vemurafenib works effectively and reduce tumor volume in some cancers however it did not show any promising effect on ATC which has BRAF ${ }^{\mathrm{V} 600 \mathrm{E}}$ mutation [27]. Thus the limited success of current chemotherapeutic regimens for ATC has led to the investigation of novel therapeutic approach and targets for the treatment. Our rationale of the study is to consider metformin (FDA approved drug used routinely for diabetes) as a potential drug to combine with vemurafenib for ATC therapy due to two major reasons. 1. In normal cells, metformin exerts anti-mitogenic effect by activation of the AMP-activated protein kinase (AMPK) and by inhibition of the MAPK pathway at the cellular level to regulate cell growth which is an important factor in insulin/IGF signalling [20]. 2. Recently, in cancer cells it has been demonstrated that metformin possess anti-tumorigenic properties and proven to inhibit cell proliferation, invasion and migration in most of the cancer cells. It appears to affect multiple key processes related to cell growth, proliferation, and survival [27-30]. To proceed with our hypothesis, Metformin, Vemurafenib and 5-Azacytidine were docked with TSHR protein using iGEMDock software to determine the docking scores in which the protein-ligand interaction were successful in identifying that the drugs were docked with TSHR with common binding site sharing between metformin and vemurafenib. Hence in the present work, combinational treatment (AMPK activator Metformin and BRAF inhibitor Vemurafenib) was studied on Anaplastic BRAF mutant cells in which our results demonstrated that combination of metformin with vemurafenib can inhibit the cellular proliferation followed by induction of apoptosis in ATC. Our results demonstrate metformin is targeting specifically on BRAF mutant anaplastic cells and did not show any effect on $\mathrm{HTH} 7$ cells (BRAF ${ }^{\mathrm{wt}}$ ATC cell line) and BCPAP differentiated cells (BRAF ${ }^{\mathrm{V} 600 \mathrm{E}}$ mutant, PTC cell line), whereas vemurafenib inhibited the proliferation of BCPAP cells and did not show any significant effect on BRAF wild type HTH7 cells. Differentiated thyroid cancer has better prognosis because the cells express sodium-iodide symporter [NIS] and can be targeted by radioactive ${ }^{131}$ I whereas undifferentiated thyroid carcinomas do not express sufficient NIS and hence radioactive ${ }^{131}$ I will not be taken by cancer cells; thereby leading to difficulty in treating anaplastic cancer cells [31]. lodide-metabolizing genes like NIS, TSHR, TG, TPO, FOXE1 and TTF are found to be methylated in ATC and hence their expression levels are silenced [32]. In our study, we showed metformin act as a demethylating agent by activating the expression of NIS, TSHR, TG and TTF in BRAF mutant anaplastic cells which was assessed by RT-PCR and Western blot. Several studies demonstrated that activation of AMPK causes cell-cycle arrest and shuts down processes that consume energy through modulation of several signaling pathways including CAMP and mTOR pathways [24]. In addition, AMPK as a cellular energy sensor are involved in catabolic pathways to replenish cellular ATP stores and result in the surge of cellular AMP/ATP ratio by inhibiting ATP synthesis and and thereby preventing the activation of the enzyme adenylyl cyclase to synthesise intracellular cAMP [16]. These findings are consistent with our study that metformin activates AMPK pathway on BRAF mutant cells, down-regulates CAMP signaling and lowers intracellular cAMP level. Our results for the first time showed advances in identifying the molecular target (CAMP) in ATC. We have further proceed our study on investigating EMT process. Our results showed combinational treatment reversed the EMT pathway significantly by upregulating the 
epithelial marker E-cadherin and downregulating the mesenchymal marker vimentin which were analysed by measuring mRNA and protein expression.

\section{Conclusions}

Overall, our findings shows that vemurafenib along with metformin targets and regulates multiple signaling pathways - BRAF/ERK signaling, CAMP signaling, AMPK pathway and EMT process in anaplastic thyroid cancer cells and significantly induce apoptosis. In addition, metformin act as a demethylating agent by activating the suppressed iodine metabolising genes of anaplastic thyroid cancer cells. Metformin ability to overcome the resistance of vemurafenib implies that this diabetic drug can be used along with well-established anticancer therapies in future to treat aggressive cancers and thus our findings suggest that novel combinational therapy and therapeutic targets for this disease.

\section{Declarations}

\section{Conflict of interest}

The authors declare no conflict of interest.

\section{Data Availability}

All data generated or analysed during this study are included in this published article.

\section{Author Contributions}

VR and LD designed the study. LD conducted the literature search of the study and performed the experiments. SR performed Bioinformatics work. The study was supervised by VR, DK, KA and KR. VR and LD analysed and validated the data and wrote the manuscript. All authors had read the manuscript and approved the publication of this manuscript.

\section{Acknowledgement}

The authors deeply thank BRNS, DST-Women scientist, Government of India for providing financial support for this research work. We sincerely thank Dr. D. Karunagaran, Head, Department of Biotechnology, Bhupat \& Jyoti Mehta School of Biosciences, IIT Madras for allowing the access to the laboratory.

\section{References}

[1] J. Lee, J.-A. Hwang, and E. K. Lee, "Recent Progress of Genome Study for Anaplastic Thyroid Cancer," Genomics Inform., vol. 11, no. 2, p. 68, 2013, doi: 10.5808/gi.2013.11.2.68. 
[2] R. C. Smallridge, L. A. Marlow, and J. A. Copland, "Anaplastic thyroid cancer: Molecular pathogenesis and emerging therapies," Endocrine-Related Cancer. 2009, doi: 10.1677/ERC-08-0154.

[3] Y. Nobuhara et al., "Efficacy of epidermal growth factor receptor-targeted molecular therapy in anaplastic thyroid cancer cell lines," Br. J. Cancer, vol. 92, no. 6, pp. 1110-1116, 2005, doi: 10.1038/sj.bjc.6602461.

[4] S. H. Chung et al., "Peroxisome proliferator-activated receptor gamma activation induces cell cycle arrest via the p53-independent pathway in human anaplastic thyroid cancer cells," Japanese Journal of Cancer Research. 2002, doi: 10.1111/j.1349-7006.2002.tb01245.x.

[5] N. ONODA et al., "Significant cytostatic effect of everolimus on a gefitinib-resistant anaplastic thyroid cancer cell line harboring PI3KCA gene mutation," Mol. Clin. Oncol., 2015, doi: 10.3892/mco.2015.496.

[6] N. Pozdeyev et al., "Genetic analysis of 779 advanced differentiated and anaplastic thyroid cancers," Clin. Cancer Res., vol. 24, no. 13, pp. 3059-3068, 2018, doi: 10.1158/1078-0432.CCR-18-0373.

[7] M. R. M. Hussain et al., "BRAF gene: From human cancers to developmental syndromes," Saudi J. Biol. Sci., vol. 22, no. 4, pp. 359-373, 2015, doi: 10.1016/j.sjbs.2014.10.002.

[8] M. Xing, "BRAF mutation in thyroid cancer," Endocr. Relat. Cancer, vol. 12, no. 2, pp. 245-262, 2005, doi: 10.1677/erc.1.0978.

[9] H. Davies et al., "Mutations of the BRAF gene in human cancer," Nature, 2002, doi: $10.1038 /$ nature00766.

[10] G. Riesco-Eizaguirre and P. Santisteban, "Molecular biology of thyroid cancer initiation," Clin. Transl. Oncol., vol. 9, no. 11, pp. 686-693, 2007, doi: 10.1007/s12094-007-0125-1.

[11] D. Russo, G. Damante, E. Puxeddu, C. Durante, and S. Filetti, "Epigenetics of thyroid cancer and novel therapeutic targets," J. Mol. Endocrinol., vol. 46, no. 3, 2011, doi: 10.1530/JME-10-0150.

[12] R. Ma, S. Bonnefond, S. A. Morshed, R. Latif, and T. F. Davies, "Stemness is derived from thyroid cancer cells," vol. 5, no. July, pp. 1-8, 2014, doi: 10.3389/fendo.2014.00114.

[13] X. Zhang et al., "MicroRNA 483-3p targets Pard3 to potentiate TGF- $\beta$ 1-induced cell migration , invasion , and epithelial - mesenchymal transition in anaplastic thyroid cancer cells," pp. 699-715, 2019, doi: 10.1038/s41388-018-0447-1.

[14] M. N. Nikiforova et al., "BRAF Mutations in Thyroid Tumors Are Restricted to Papillary Carcinomas and Anaplastic or Poorly Differentiated Carcinomas Arising from Papillary Carcinomas," J. Clin. Endocrinol. Metab., 2003, doi: 10.1210/jc.2003-030838. 
[15] S. Jin, O. Borkhuu, W. Bao, and Y.-T. Yang, "Signaling Pathways in Thyroid Cancer and Their Therapeutic Implications," J. Clin. Med. Res., vol. 8, no. 4, pp. 284-296, 2016, doi: 10.14740/jocmr2480w.

[16] F. Niehr et al., "Combination therapy with vemurafenib (PLX4032/RG7204) and metformin in melanoma cell lines with distinct driver mutations," J. Transl. Med., vol. 9, pp. 1-13, 2011, doi: 10.1186/1479-5876-9-76.

[17] X. Y. Chan, A. Singh, N. Osman, and T. J. Piva, "Role played by signalling pathways in overcoming BRAF inhibitor resistance in melanoma," International Journal of Molecular Sciences. 2017, doi: 10.3390/ijms18071527.

[18] J. Blay et al., "HHS Public Access," vol. 373, no. 8, pp. 726-736, 2016, doi: 10.1056/NEJMoa1502309.Vemurafenib.

[19] J. Mccain, "The MAPK (ERK) Pathway Investigational Combinations for the Treatment Of BRAFMutated Metastatic Melanoma," vol. 38, no. 2, 2013.

[20] R. L. Plews et al., "A novel dual AMPK activator/mTOR inhibitor inhibits thyroid cancer cell growth," J. Clin. Endocrinol. Metab., vol. 100, no. 5, pp. E748-E756, 2015, doi: 10.1210/jc.2014-1777.

[21] G. Rena, D. G. Hardie, and E. R. Pearson, "The mechanisms of action of metformin," Diabetologia. 2017, doi: 10.1007/s00125-017-4342-z.

[22] R. A. Metcalfe, C. Findlay, W. R. Robertson, A. P. Weetman, and S. Mac Neil, "Differential effect of thyroid-stimulating hormone (TSH) on intracellular free calcium and cAMP in cell transfected with the human TSH receptor," J. Endocrinol., vol. 157, no. 3, pp. 415-424, 1998, doi: 10.1677/joe.0.1570415.

[23] K. D. Durai L, Vijayalakshmi R, "A novel reporter system for cyclic AMP mediated gene expression in mammalian cells based on synthetic transgene expression system.," doi: 0.1016/j.ejphar.2019.04.037. Epub 2019 Apr 26.

[24] T. Yau, C. Y. Lo, R. J. Epstein, A. K. Y. Lam, K. Y. Wan, and B. H. Lang, "Treatment outcomes in anaplastic thyroid carcinoma: Survival improvement in young patients with localized disease treated by combination of surgery and radiotherapy," Ann. Surg. Oncol., 2008, doi: 10.1245/s10434-008-0005-0.

[25] V. Gunda et al., "Blocks to thyroid cancer cell apoptosis can be overcome by inhibition of the MAPK and PI3K/AKT pathways," Cell Death Dis., vol. 5, no. 3, pp. e1104-13, 2014, doi: 10.1038/cddis.2014.78.

[26] B. M. Andrade and D. P. De Carvalho, "Perspectives of the AMP-activated kinase (AMPK) signalling pathway in thyroid cancer," Biosci. Rep., vol. 34, no. 2, pp. 181-187, 2014, doi: 10.1042/BSR20130134.

[27] S. Saini, K. Tulla, A. V. Maker, K. D. Burman, and B. S. Prabhakar, "Therapeutic advances in anaplastic thyroid cancer: a current perspective," Mol. Cancer, 2018, doi: 10.1186/s12943-018-0903-0. 
[28] M. K. Powell et al., "Metformin Treatment for Diabetes Mellitus Correlates with Progression and Survival in Colorectal Carcinoma," Transl. Oncol., vol. 13, no. 2, pp. 383-392, 2020, doi:

10.1016/j.tranon.2019.10.011.

[29] B. Li et al., "Metformin induces cell cycle arrest, apoptosis and autophagy through ROS/JNK signaling pathway in human osteosarcoma," Int. J. Biol. Sci., vol. 16, no. 1, pp. 74-84, 2020, doi: $10.7150 /$ ijbs.33787.

[30] H. Hakimee, P. Hutamekalin, S. Tanasawet, P. Chonpathompikunlert, V. Tipmanee, and W. Sukketsiri, "Metformin inhibit cervical cancer migration by suppressing the FAK/Akt signaling pathway," Asian Pacific J. Cancer Prev., vol. 20, no. 12, pp. 3539-3545, 2019, doi: 10.31557/APJCP.2019.20.12.3539.

[31] H. Zhang and D. Chen, "Synergistic inhibition of MEK/ERK and BRAF V600E with PD98059 and PLX4032 induces sodium/iodide symporter (NIS) expression and radioiodine uptake in BRAF mutated papillary thyroid cancer cells," Thyroid Res., vol. 11, no. 1, pp. 1-6, 2018, doi: 10.1186/s13044-018-00576.

[32] García-Jiménez \& Santisteban. TSH Signalling and Cancer. Arq Bras Endocrinol Metab 2007; Arquivos Brasileiros de Endocrinologia \& Metabologia. 51(5):654-71 (2007).

\section{Tables}

Table 1: Binding energy and Hydrogen bond interaction of drugs (ligands) with TSHR (protein)

\begin{tabular}{|l|l|l|l|l|l|}
\hline LIGAND & $\begin{array}{l}\text { TOTAL } \\
\text { ENERGY }\end{array}$ & VDW & H BOND & ELEC & AVERCON PAIR \\
\hline $\begin{array}{l}\text { TSHR with } \\
\text { Metformin }\end{array}$ & -65.1694 & -44.1694 & -21 & 0 & 32.8889 \\
\hline $\begin{array}{l}\text { TSHR with } \\
\text { Vemurafenib }\end{array}$ & -113.236 & -94.2821 & -18.9543 & 0 & 24.1667 \\
\hline $\begin{array}{l}\text { TSHR with } \\
\text { 5-Azacytidine }\end{array}$ & -114.015 & -69.6287 & -44.3863 & 0 & 36.8824 \\
\hline
\end{tabular}

Table 2: Table 2 is not available with this version.

\section{Figures}


a. TSHR with Metformin

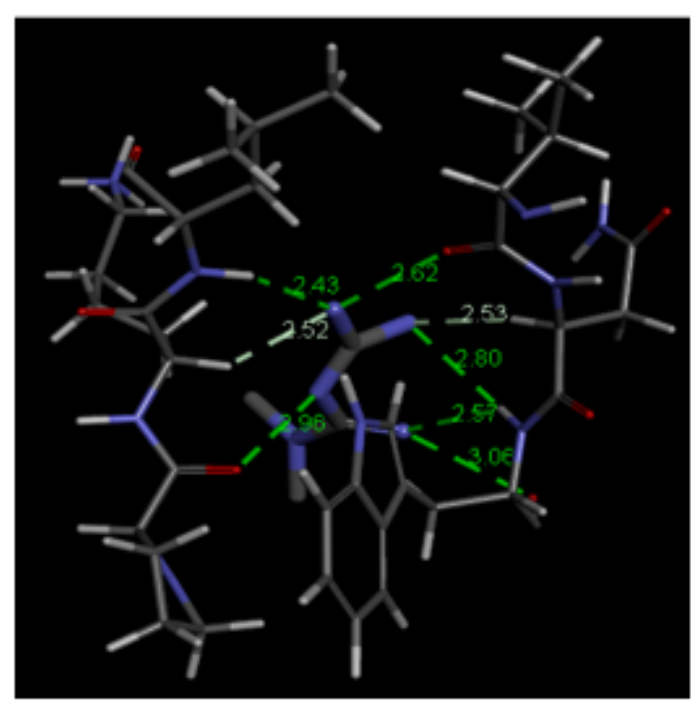

c. TSHR with 5-Azacytidine

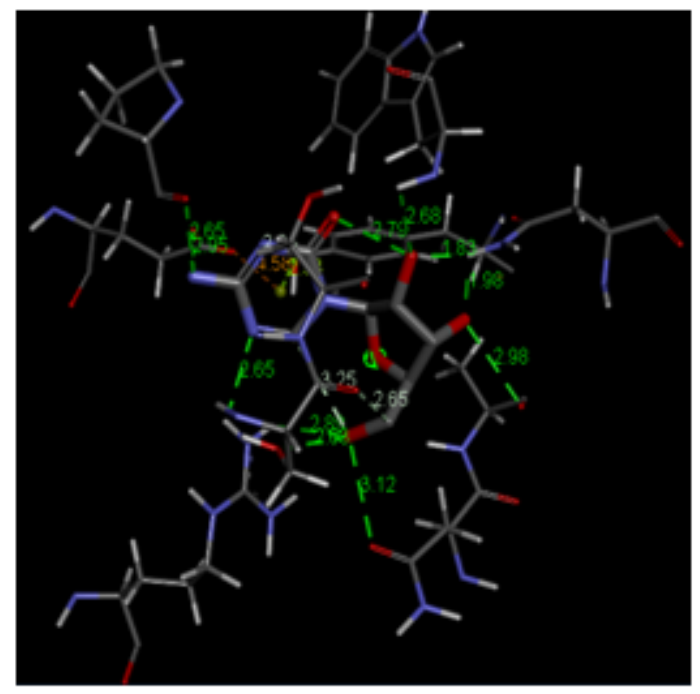

b. TSHR with Vemurafenib

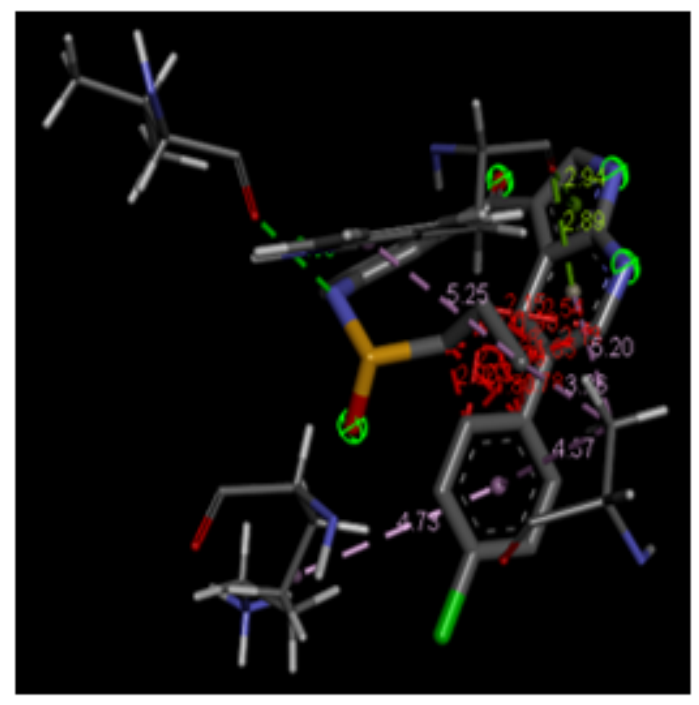

d. TSHR with Metformin and Vemurafenib

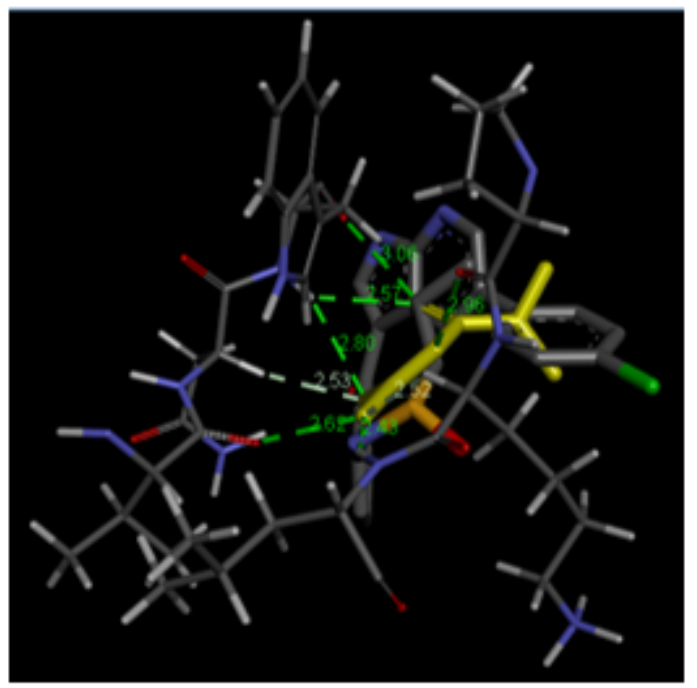

Figure 1

Molecular docking of TSHR with a. Metformin, b. Vemurafenib, c. 5-Azacytidine and d. Metformin and Vemurafenib using iGEMDOCK software 
a

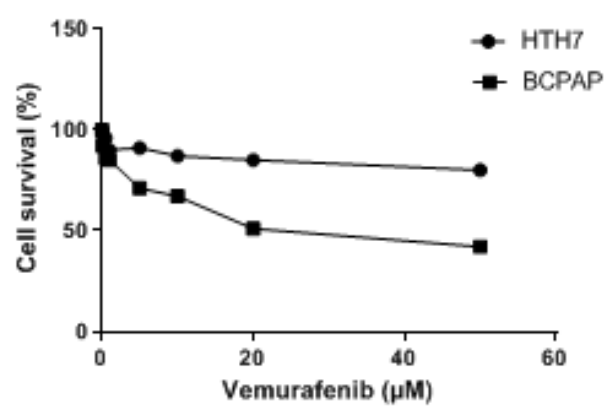

c

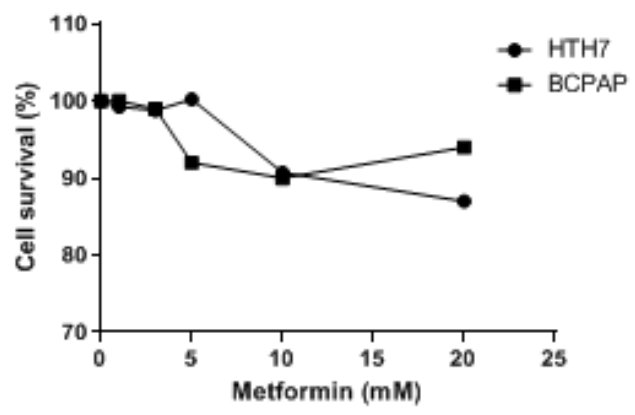

b

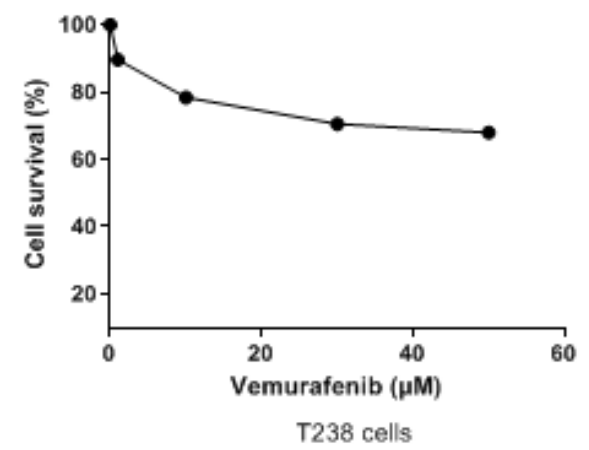

d

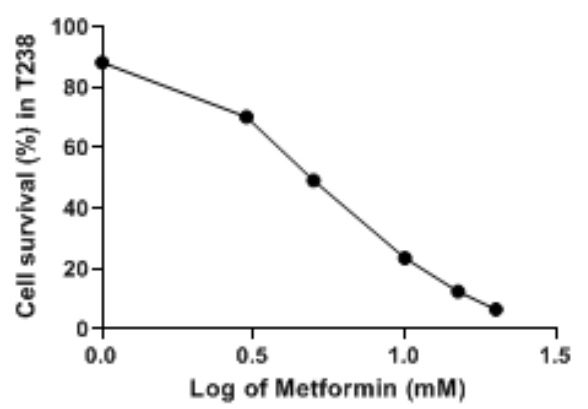

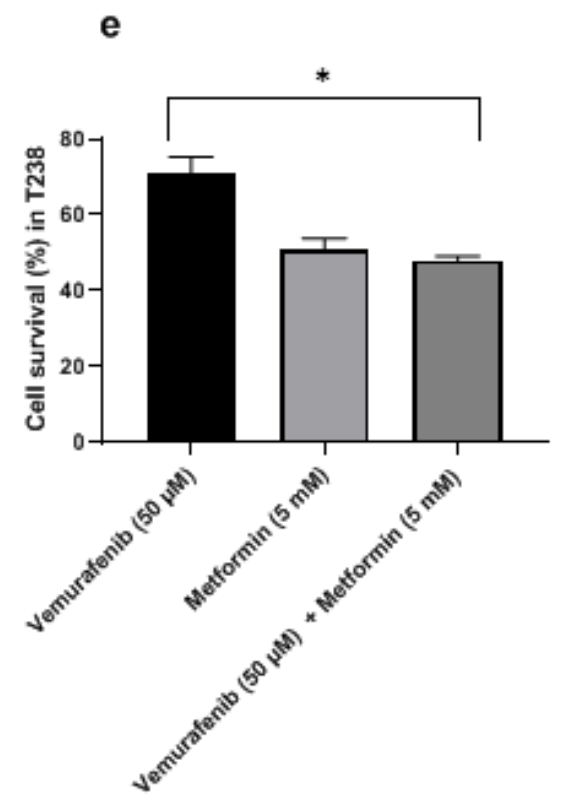

Figure 2

Effect of Vemurafenib and Metformin on proliferation of different thyroid cancer cell lines a. Effect of vemurafenib in different thyroid cancer cell lines. HTH7 (BRAFWT ATC cell line), BCPAP (BRAFV600Emutant, PTC cell line) cells and b. T238 cells were treated with or without different concentrations of Metformin as a single agent, incubated for $48 \mathrm{~h}$ and the percentage of surviving cells with respect to controls were determined by MTT assay respectively. c. Dose dependent effect of 
metformin on T238 cells. T238 cells were treated with different concentrations of Metformin and measured the cytotoxicity using MTT assay after $48 \mathrm{~h}$. d. Treatment of T238 cells with different concentrations of vemurafenib along with $5 \mathrm{mM}$ of Metformin, incubated for $48 \mathrm{~h}$ and the percentage of surviving cells with respect to controls (untreated) were determined by MTT assay. e. Combinational treatment of Vemurafenib and metformin on T238 cells. Each data point represents the mean of at least three independent experiments in triplicates. ( ${ }^{*}, \mathrm{P}<0.05$; $* *, \mathrm{P}<0.01$; and $\left.* \star \star, \mathrm{P}<0.001\right)$ vs control.

a

b

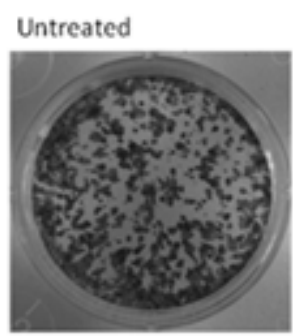
$5 \mathrm{mM}$ Metformin

$50 \mu \mathrm{M}$ Vemurafenib
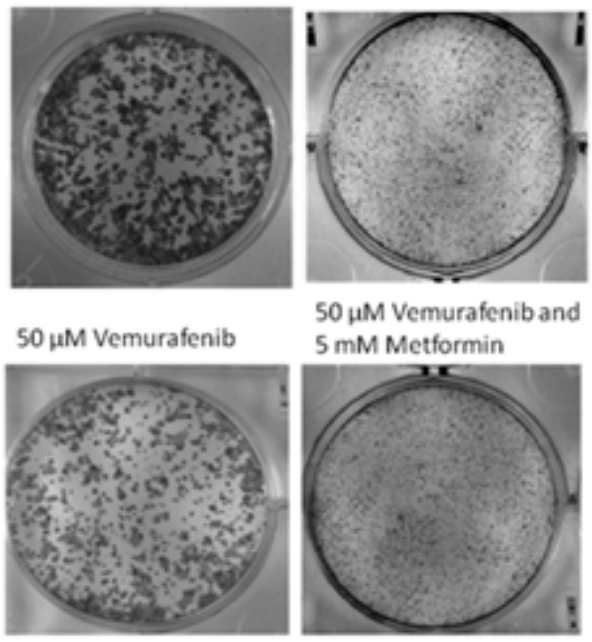

$50 \mu \mathrm{M}$ Vemurafenib and $5 \mathrm{mM}$ Metformin
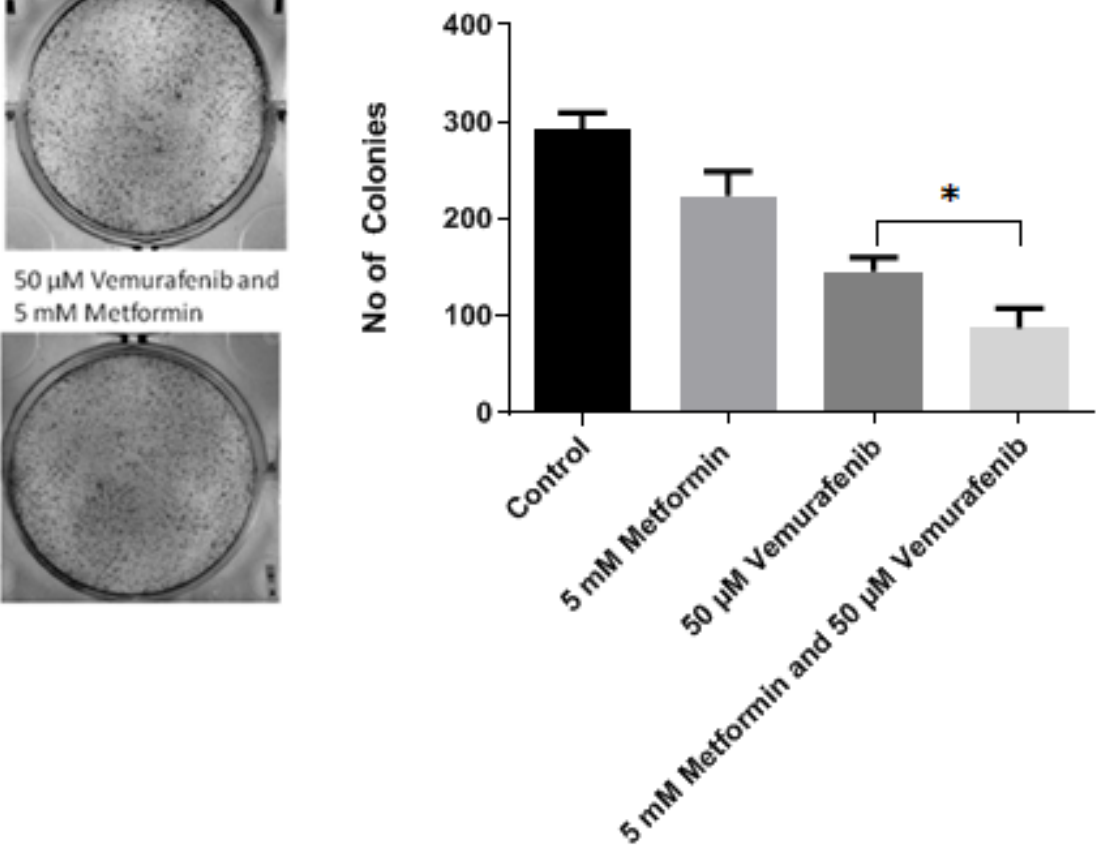

\section{Figure 3}

Effect of Metformin and Vemurafenib on colony formation of anaplastic thyroid cancer cell line T238. a. T238 cells were treated with $5 \mathrm{mM}$ metformin, $50 \mu \mathrm{M}$ vemurafenib or their combination and incubated for 14 days till the formation of colonies. Cells were then fixed with methanol and stained with Crystal violet. b. Number of colonies formed in metformin, vemurafenib or the combination of both treated group were compared to the number of colonies formed in untreated control group. $\left({ }^{*}, \mathrm{P}<0.05\right.$; $\star \star, P<0.01$; and ${ }^{\star \star \star}, \mathrm{P}$ $<0.001)$ vs control. 
a

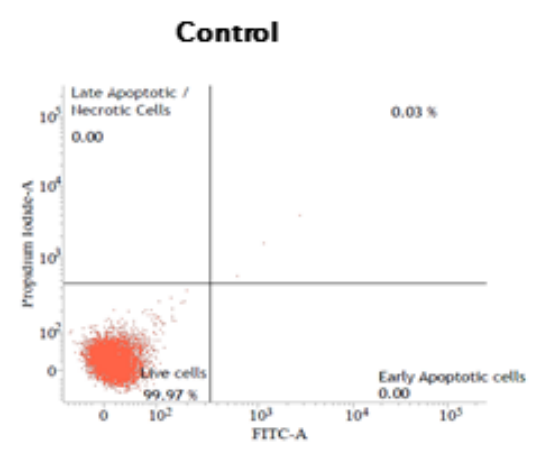

$50 \mu M$ Vemurafenib

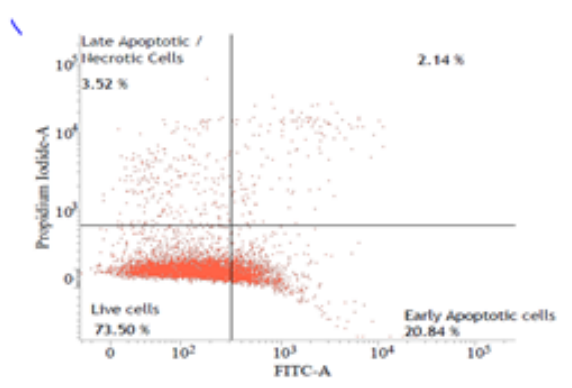

b
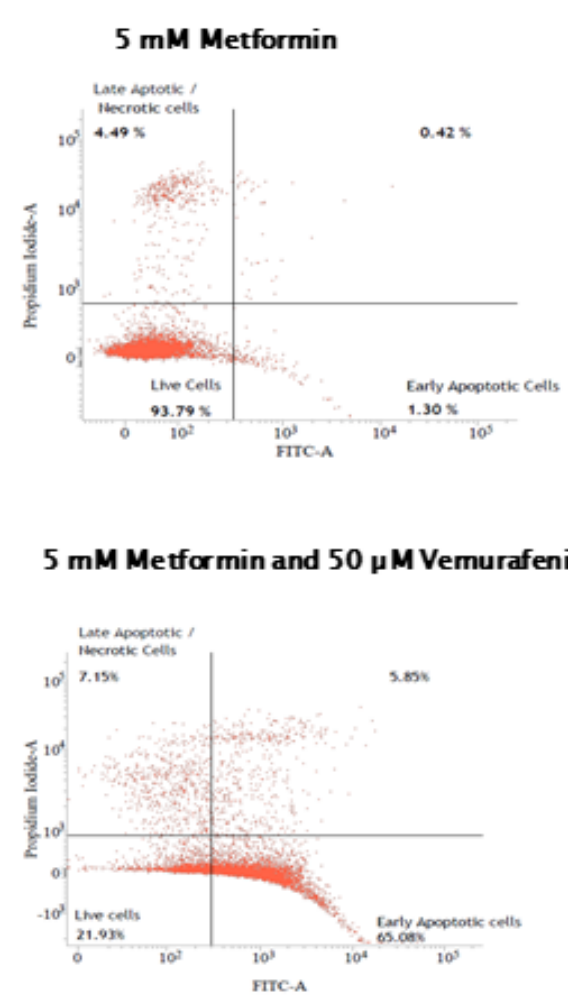

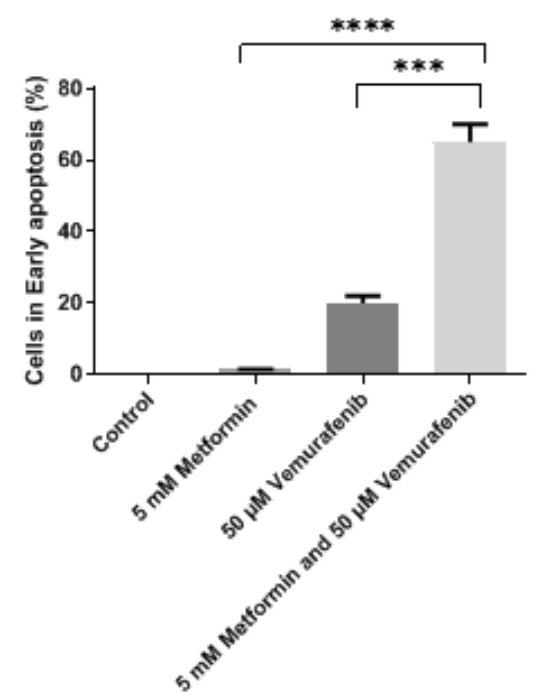

Figure 4

Effect of Metformin, Vemurafenib or their combination on apoptosis To test the effects of the different treatments, anaplastic thyroid cells were treated for $48 \mathrm{~h}$ without (control) or with $5 \mathrm{mM}$ metformin, 50 $\mu \mathrm{M}$ vemurafenib or their combination. Cells were stained with Annexin $\mathrm{V}$ and $\mathrm{PI}$ and were analyzed by flowcytometry. Percentages are shown in relation to the control. b. Percentage of early apoptotic cells formed in metformin, vemurafenib or the combination of both treated group were compared to the number of colonies formed in untreated control group. ( ${ }^{*}, \mathrm{P}<0.05$; $* *, \mathrm{P}<0.01$; and $* \star *, \mathrm{P}<0.001$ ) vs control. 
a

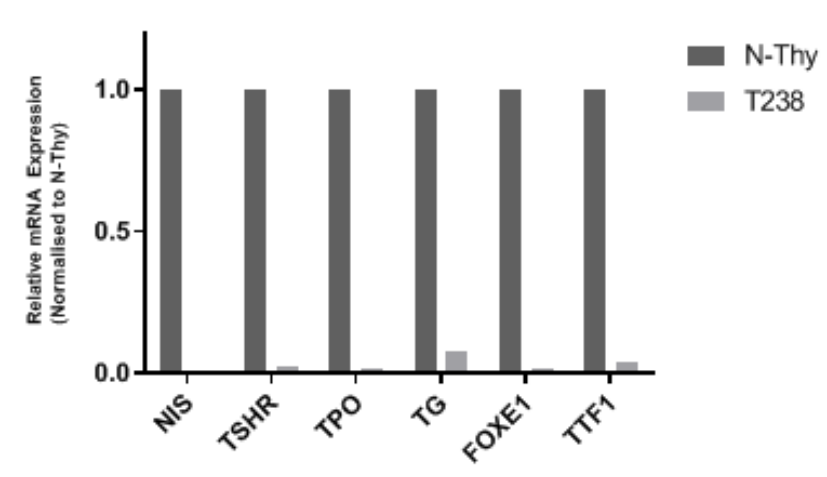

b

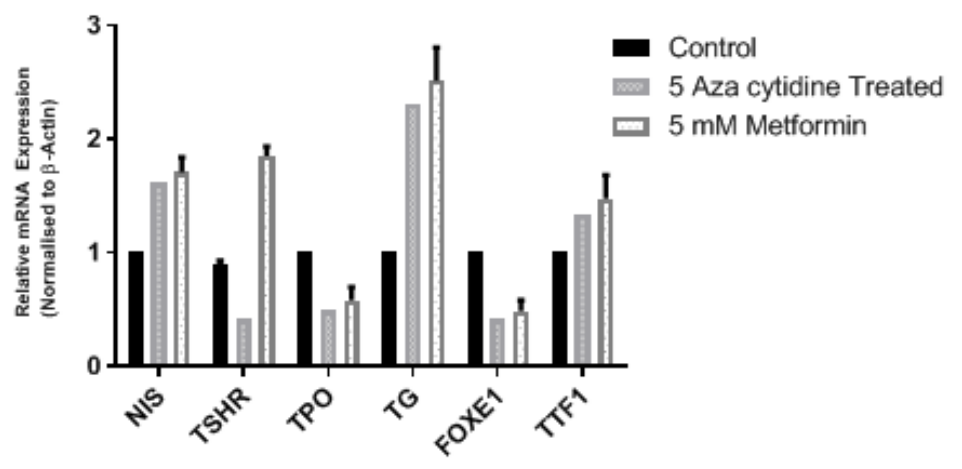

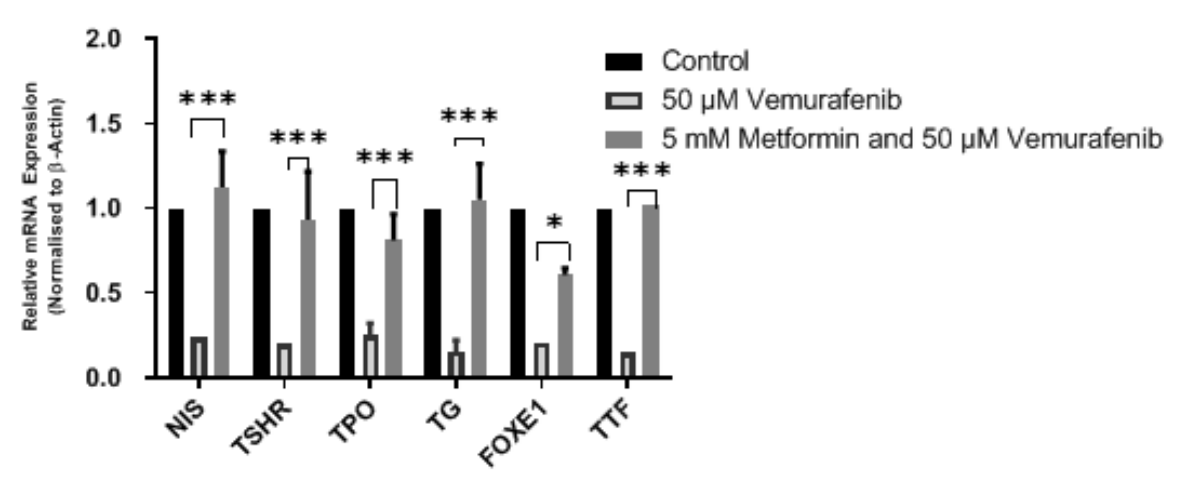

Figure 5

a. qPCR was performed to estimate the mRNA expression levels of different genes inT238 cells that are involved in iodide metabolism and the expression levels were calculated relative to normal thyroid cancer cell line N-Thy. b. estimation of mRNA expression levels after $48 \mathrm{~h}$ of treatment with $10 \mu \mathrm{M}$ 5-Azacytidine and $5 \mathrm{mM}$ of metformin in T238 cells. c. estimation of mRNA expression levels after $48 \mathrm{~h}$ of treatment with $5 \mathrm{mM}$ of metformin and $50 \mu \mathrm{M}$ vemurafenib or the combination. The quantification of each mRNA level is performed by using sybr green chemistry and is calculated by 2-ddCT method; normalized internal control used is $\beta$-Actin. ( ${ }^{*}, \mathrm{P}<0.05 ; * \star, P<0.01$; and $\left.* * *, P<0.001\right)$ vs control. 

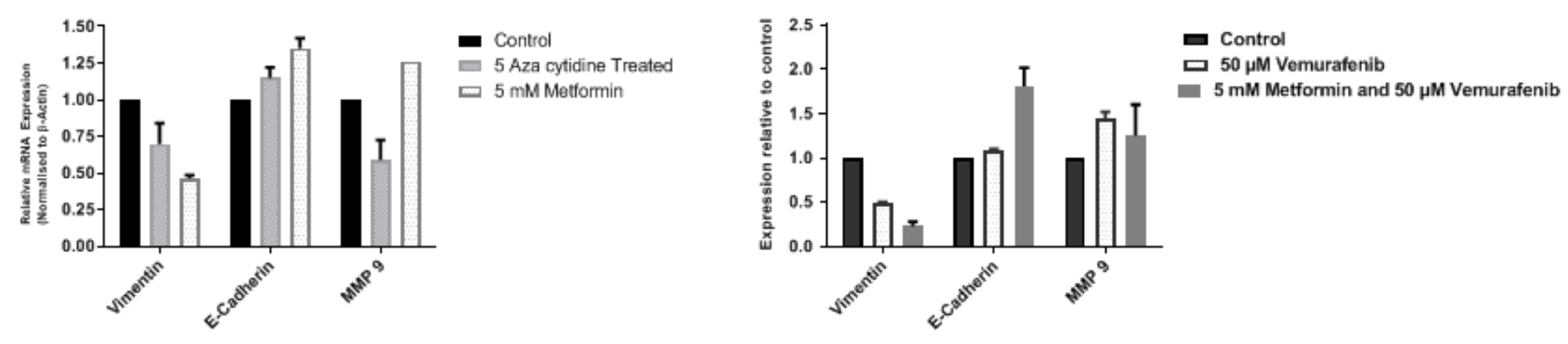

\section{Figure 6}

qRT-PCR of EMT markers and MMP-9 mRNA expression in T238 cells which were treated with or without metformin and 5-AZ cytidine (a) and which were treated with or without metformin and vemurafenib or the combination of both (b). ${ }^{*} P<0.05, * * P<0.01$, and $* * * P<0.001$, versus control
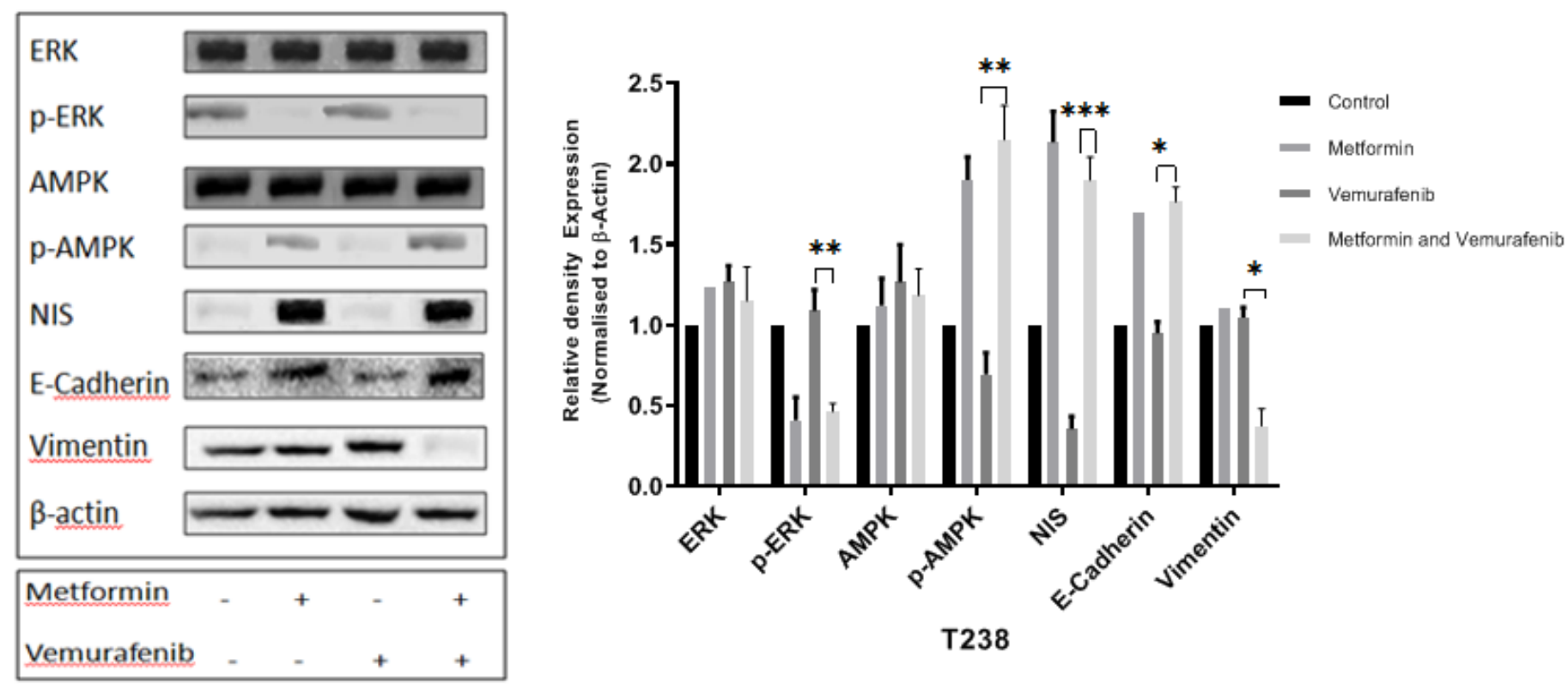

Figure 7

Whole cell lysates were obtained after $48 \mathrm{~h}$ treatment of metformin, vemurafenib or their combination, and expressions of ERK, p-ERK, AMPK, p-AMPK, NIS, E-cadherin and Vimentin were checked by Western blotting. $\beta$ - Actin was used as an internal control. Western blots are developed in ChemiDoc western blot apparatus from BioRad. Density of protein bands were quantified with respect to control. ${ }^{*} P<0.05, * \star P<$ 0.01 , and ${ }^{\star * *} P<0.001$, versus control 

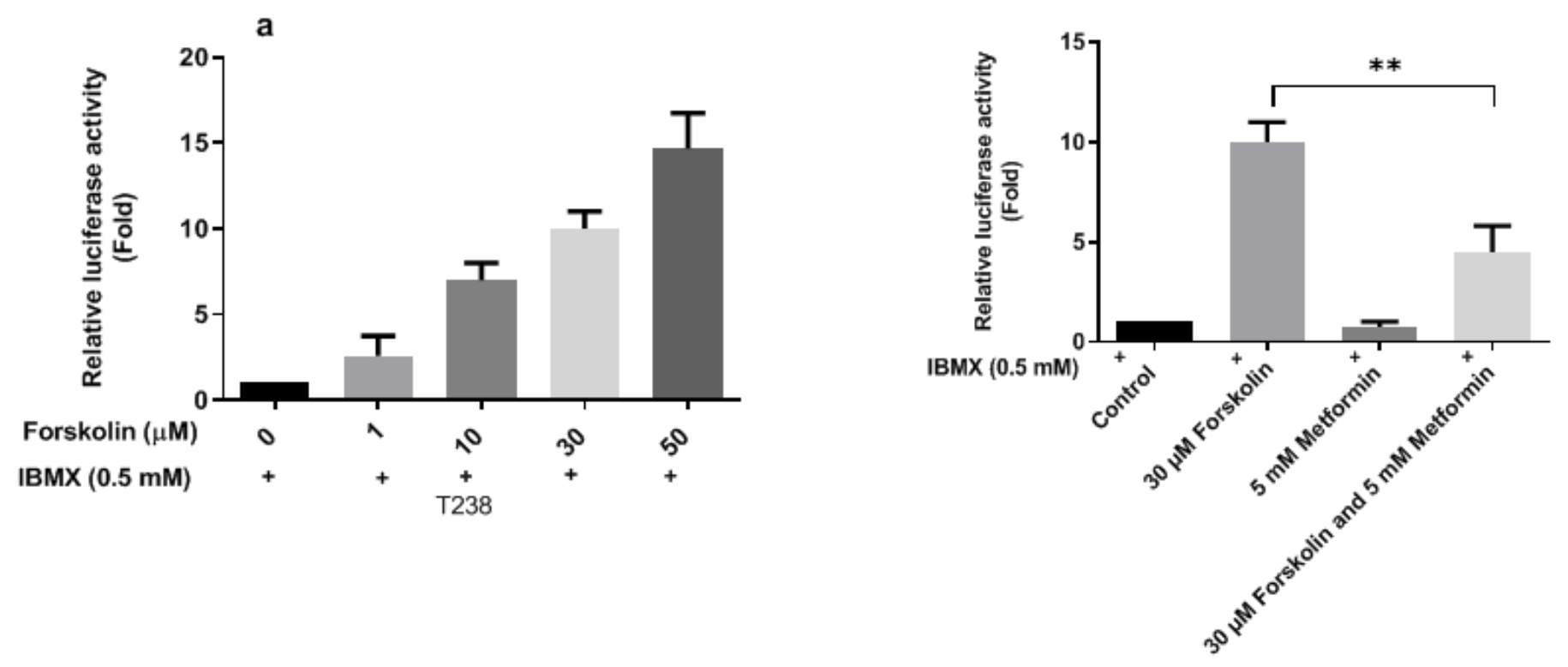

Figure 8

Determination of cAMP signaling in ATC cells and effect of Metformin on cAMP signaling: a. T238 cells were transfected with CRE (cAMP response element) reporter plasmid pGL4.29, and were treated with increasing concentration of Forskolin and measured the luciferase activity after 48 h. b. T238 cells were transfected with pGL4.29, treated with $30 \mu \mathrm{M}$ Forskolin, $5 \mathrm{mM}$ metformin or both and measured the luciferase activity after $48 \mathrm{~h}$ to identify the effect of metformin on cAMP signaling in ATC. $(*, P<0.05$; $* *$, $\mathrm{P}<0.01$; and $* \star *, P<0.001)$ vs control. 
a
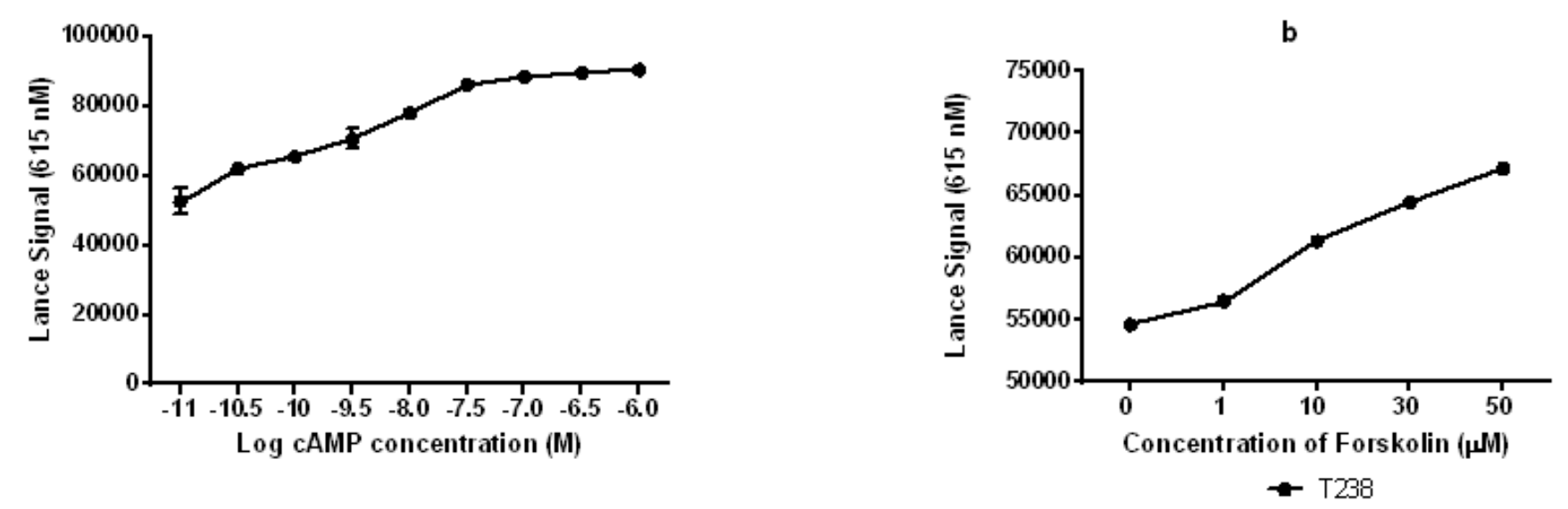

Table 1

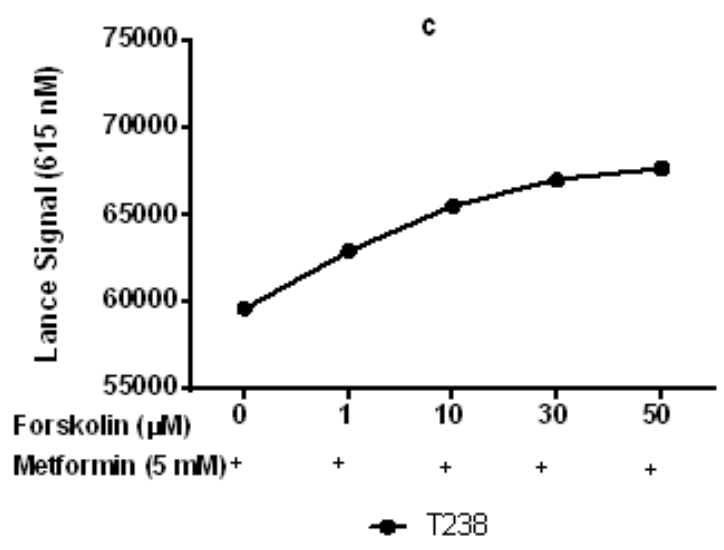

\begin{tabular}{|c|c|c|}
\hline \multirow{2}{*}{$\begin{array}{c}\text { Forskolin } \\
(\mu \mathrm{M})\end{array}$} & \begin{tabular}{c}
$|c|$ \\
CAMP (nM) \\
\cline { 2 - 3 }+ Metformin
\end{tabular} & $\begin{array}{c}\text { T238 } \\
\text { - Metformin }\end{array}$ \\
\hline 0 & 0.03 & 0.05 \\
\hline 1 & 0.05 & 0.05 \\
\hline 10 & 0.1 & 0.1 \\
\hline 30 & 0.25 & 0.16 \\
\hline 50 & 0.3 & 0.2 \\
\hline
\end{tabular}

\section{Figure 9}

Effect of Metformin on intracellular cyclic AMP level a. A standard curve for cAMP was performed by using different concentrations of cAMP diluted from the cAMP standard stock and measured the fluorescence intensity (Lance signal) at $615 \mathrm{~nm}$. b. Forskolin dose responsive curves of T238 cell line. Cells were treated with or without Metformin and Forskolin and were harvested with a non enzymatic cell dissociation solution versene and then the assays was performed as per Perkin Elmer manufacturer's protocol by testing 3000 cells per well in 96 wells opti-plate with different concentrations of Forskolin. Then the Lance signal was measured at $615 \mathrm{~nm}$ on PerkinElmer EnVision instrument after $2 \mathrm{~h}$ of Forskolin

\section{Supplementary Files}

This is a list of supplementary files associated with this preprint. Click to download.

- Scheme1.png 
- Scheme2.png

Page 24/24 